\title{
Application of thermography for diagnosis of central heating elements
}

\author{
by Z. Rymarczyk¹, R. Rabjasz, M. Dzierzgowski, S. Turlejski ${ }^{2}$,
}

1. Institute of Heating and Sanitary Technology, 26-600 Radom, ul. Wilcza 8, E-mail: Rymarczyk@radom.medianet.pl

2. The Warsaw University of Technology, Institute of Heating and Ventilating, E-mail: Mieczyslaw.Dzierzgowski@is.pw.edu.pl or Stefan.Turlejski@is.pw.edu.pl

\begin{abstract}
In the report temperature distributions on surface of radiators in laboratory and exploitation conditions is presented. It is qualified, for steel panel radiator, place equivalent to average temperature of surface and difference between temperature given for $75 \%$ of radiator's height and the average temperature for different water jets. The results of these examinations have meaning in improvement of account of heating costs on the basis of values indicated on heating costs divisors mounting on radiator's surface. Also examples thermal pictures of radiators are presented in conditions of incorrectly working central heating installation.
\end{abstract}

\section{Introduction}

In research project [3] the correctness of location heat costs divisors on surface of radiator was estimated initially. In accordance with standard requirements (PN-EN 834 and 835) for location place of assembling of heat costs divisors should be chosen such places which in possibly big range of work sufficient dependence between indicated value and emission heat to the environment exists in wide range of work of the installation. The heat costs divisors are assembled usually at $75 \%$ of radiator's height. In initial examinations it is attempted to find such a location of divisors on radiator's surface where proportionality of indications to thermal power exists. For representative point place on radiator's surface equivalent to his average temperature was acknowledged initially. The examinations were led in conditions of steady heat exchange " radiator-accommodation" for temperature distribution on radiator's surface in conditions of correctly working installation. For initial analysis of correctness of divisor's location, the station to thermal examinations of radiators with open chamber and apparatus AGEMA 470 Pro was used.

The report shows also examples of thermal pictures of radiators in conditions of incorrectly working central heating installation. In the research project [3], among other things, temperature distribution on surface of radiators in conditions of incorrectly working installation was examined. These conditions are caused the existence of air, refuses and wrong hydraulic adjustment of central heating installation. The disturbances in the exchange of heat, caused by these occurrences, convey information about correctness of central heating installation' workings.

\section{Method}

The selected types of panel steel and cast-iron radiators were examinated at the station to thermal examinations of radiators with open chamber. Water temperature at inflow and outflow of radiator, air temperature, water jet and other parameters were measured. The obtained results of measurements made possible qualification of radiator's thermal power. At the moment of steady heat exchange "radiator - accommodation", temperature distribution on frontal surface of radiator was registered by means of the apparatus AGEMA 470 Pro. The obtained thermal pictures permitted to find a position of a representative point in half of length of radiator. Then, the electronic divisors of heating costs were installed on surface of radiator in universally used place ( $75 \%$ of height) and in the representative point. The speed 
of divisors' countings was examined. The researches were led for two water jets, different from each other 4 times.

In further stage the thermograms in conditions of incorrectly working central heating installation were obtained.

\section{Results}

In Fig. 1, results of examinations of representative point's position for frontal surface of steel panel radiator for different water jets are presented. The Fig. 1 shows that location of representative point was approximately in half of height of radiator $(52,9 \div 47,4 \%$ of radiator's height) of examined radiators for water jets changing in range from $0,00353 \mathrm{~kg} / \mathrm{s}$ to 0,01982 $\mathrm{kg} / \mathrm{s}$ [4]. The similar results were obtained for other radiators. Additionally, a certain regularity was observed, that for exponentially increasing water jet, position of representative point dropped according to power function. The results of measurements of speed of countings of electronic divisors at two heights confirmed the initial argument, that proportionality of indications of the divisors to thermal power obtains for installing them at half of radiator's height.

The temperature at $75 \%$ of height of radiator exceeds the temperature surface estimated at the representative point [5]. The quantity of the exceeding influences on speed of countings of divisor and it depends from water jet. In the case of diminution of water jet in the examined radiator 5,6 times, value of the exceeding of temperature changed 3, 3 times; if the water jet increases then the value of the exceeding decreases. The values of exceeding of temperature estimated at $75 \%$ of radiator's height and temperature in the represantative point, for radiator DE' LONGHI type 10, are presented in Fig. 2 [5]. For different types of the examined radiators it was obtained similar results.

During assembly the divisor is usually located in half of the radiator's lengths. In the case of cast - iron column radiators this rule is possible only under the condition of even numbers of elements. In the case of odd numbers of elements the equal rule of assembly with shift of the divisor towards termostatical valve is obligatory. Does this shift have influence on the increasing indications of the divisor? In Fig. 3 the temperature distribution on surface of radiator is presented in function of its lenght at half and at $75 \%$ of its height $[4,5]$. The graph presents the increase of the temperature at $75 \%$ of height of radiator, for the given water jet, in the case of the shift in direction to the inflow of radiator. Such dependence is negligible at half of radiator's height.

In conditions of exploitation, the temperature distribution on surface of radiators can considerably differ from shape of distribution obtained in laboratory conditions. It can be a reason of incorrect accountses of heating costs on the basis of indications of the divisors. The thermal image on surface of steel panel with air and after deaerating is presented in Fig. 4. In Fig. 5 the thermal images of inflow zone of cast-iron radiator before cleaning of installation and after cleaning are showed. Fig. 6 presents the examples of radiator's thermogram obtained during their exploitation in the case of incorrect workings of central heating installation. The main reasons of defects of used at present systems to accountses of heating's costs on the basis of indications of heat costs divisors and general requirements to existing central heating installation in habitable building, where systems of individual accountses of heating's costs was introduced, are presented in [1,2].

\section{Conclusions}

On the basis of the temperature distribution measured on the surface of radiators the following conclusions can be established:

- for the examined radiators the place of the average temperature of radiator's frontal surface was found approximately at half of height for several times differing water jets; the position of these places depends on the values water jet, 
http://dx.doi.org/10.21611/ğirt.2000.027

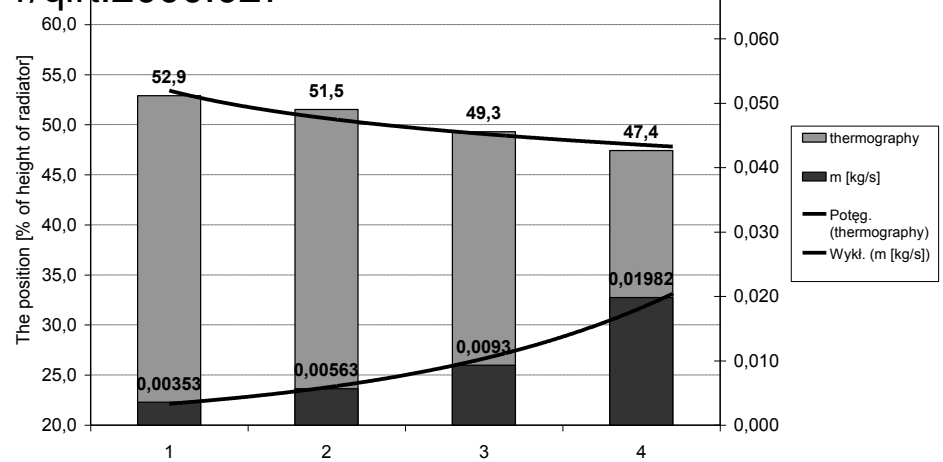

- assumming temperature of radiator's surface at $75 \%$ of height as representative, causes significiant error in the examined range of water jets; this error depends on water jet,

- in energetic audits of the buildings, where thermography was used mainly for estimations of heat losses through external walls, this method also can be used to initial estimations of correctness of central heating installation workings; in the real and laboratory conditions, obtained the temperature distribution on surface of central heating installation elements in the case of existence of air and refuses or wrong of hydraulic adjustment of central heating installation; these occurrences cause disturbances in heat exchange " radiator - accommodation" and influence temperature values on radiator's surface and shape of temperature distribution. Consequently, it leads incorrect accountses of costs heating on the basis of indications of the heating cost divisors,

- defects of thermal insulation in the walls can be reason of incorrect accountses as well.

\section{Literature}

[1] DZIERZGOWSKI, M.," Main reasons of defects of used at present systems to accountses of heating's costs on the basis of indications of heat costs divisors", I All-Polish Conference PROBLEMS OF ACCOUNTSES OF INDIVIDUAL COSTS OF HEATING, Jedlnia/Radom, 11-12. 05. 2000 (in polish language)

[2] RABJASZ, R.," General requirements to existing central heating installation in habitable building, where system of individual accountses of heating's costs, dependent from use of heat, is introduces ", I All-Polish Conference PROBLEMS OF ACCOUNTSES OF INDIVIDUAL COSTS OF HEATING, Jedlnia/Radom, 11-12. 05. 2000 (in polish language) [3] RABJASZ, R., RYMARCZYK, Z., TURLEJSKI, S., HIBNER, W., DZIERZGOWSKI, M., BISCHOFF, S.: " The influence size of radiator, locations and other factors on thermal power and temperature distribution on its surface in laboratory and real conditions", Research project No 7T07G01208p02 financed by The Committee Of Scientific Researches, 1995 $\div 1997$, Institute of Heating and Sanitary Technology, Radom (in polish language)

[4] RYMARCZYK, Z.," The temperature disrtibutions on surface of radiators in conditions of laboratory and incorrectly working heating installation ", I All-Polish Conference PROBLEMS OF ACCOUNTSES OF INDIVIDUAL COSTS OF HEATING, Jedlnia/Radom, 11-12. 05. 2000 p $45 \ldots 53$ (in polish language)

[5] RYMARCZYK, Z., "Use of thermography to examinations of temperature distribution on surface of elements of central heating installation", doctor's thesis, The Warsaw University of Technology, 1999 (in polish language) 
Figure 1. The position of the representative point for frontal surface of radiator for different values of water jets

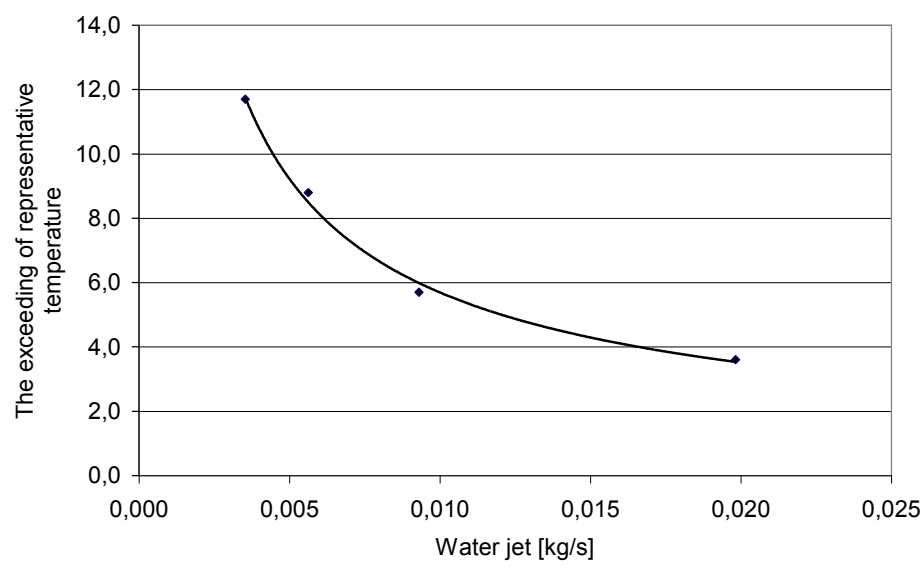

Figure 2. The values of exceedings of temperature estimated at $75 \%$ of radiator's height and temperature in the represantative point (DE' LONGHI type 10)

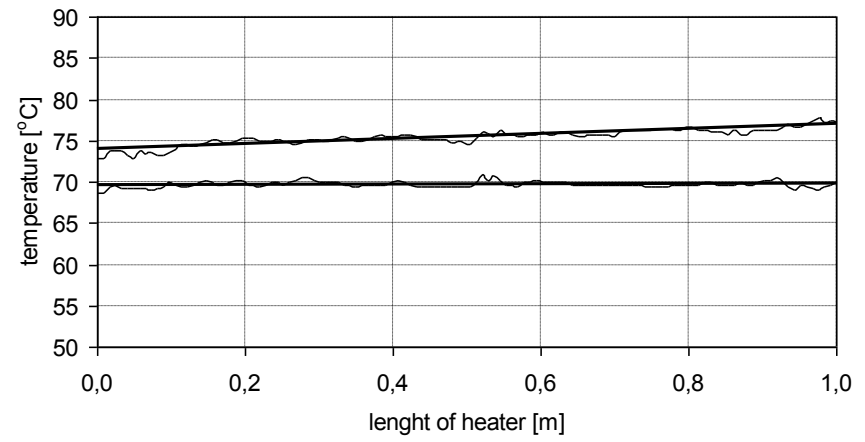

Figure 3. The dependence of temperature estimated in half and $75 \%$ of radiator's height in function of lenght, for water jet $0,00563 \mathrm{~kg} / \mathrm{s}$ (DE' LONGHI type 10)
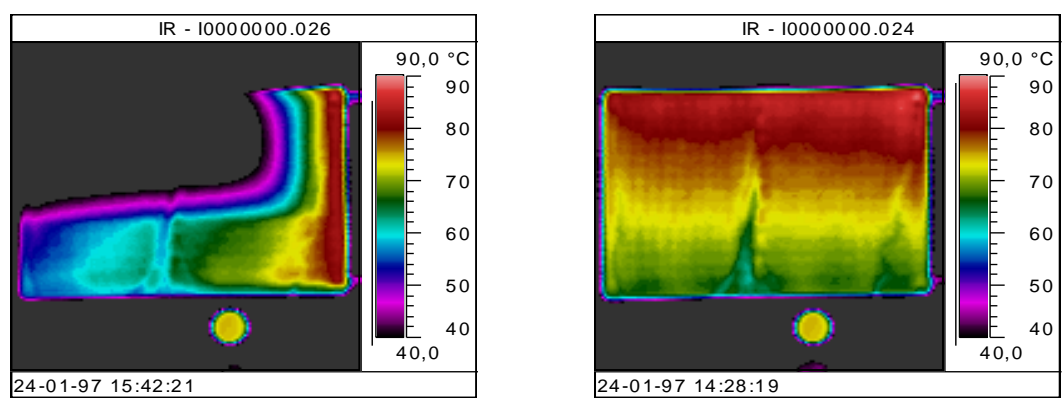

Figure 4. Thermograms of radiator a) with the air b) after deaerating.
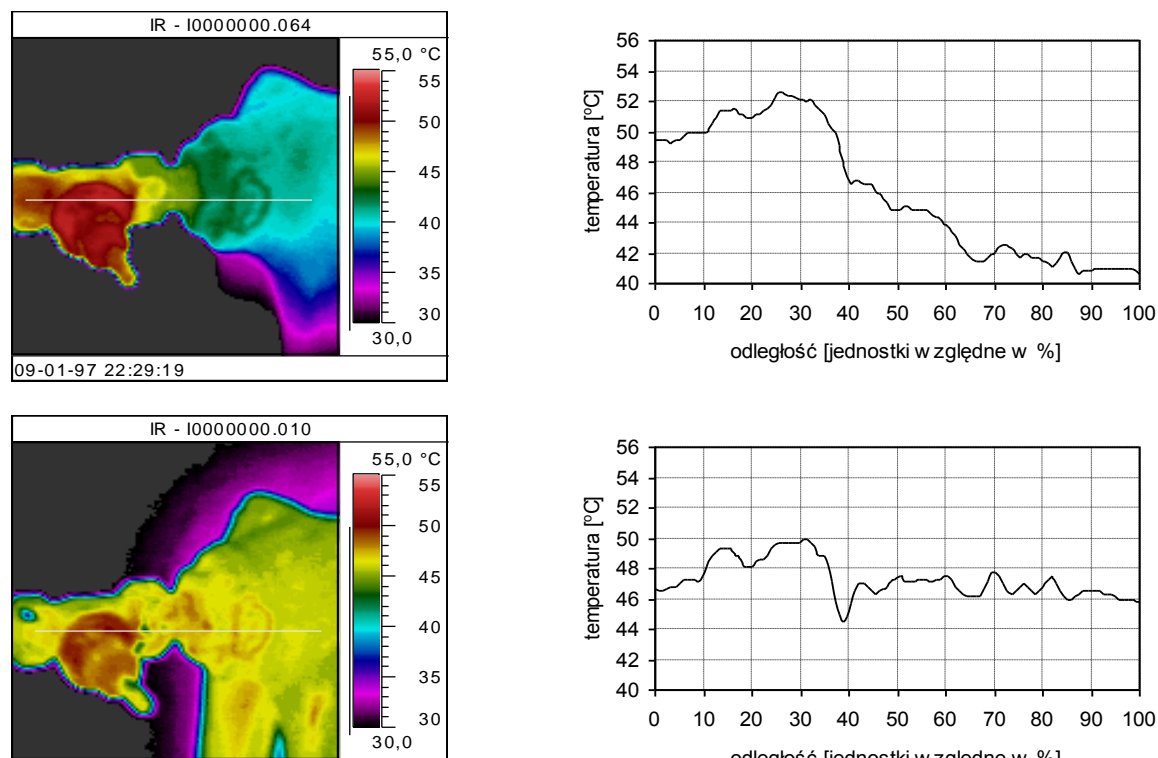
http://dx.doi.org/10.21611/qirt.2000.027

Figure 5. Thermograms of inflow zone of radiator before cleaning of installation and after cleaning

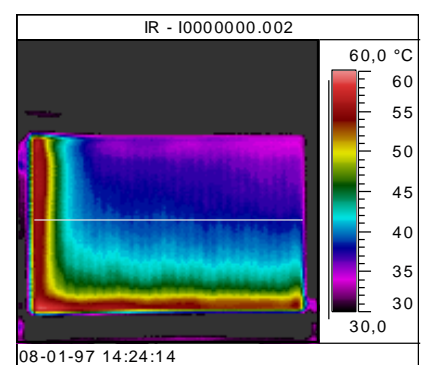

$\mathbb{R}-10000000.004$

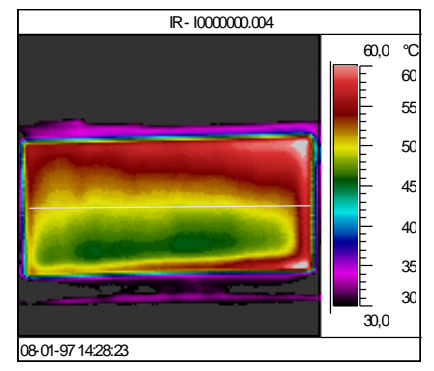

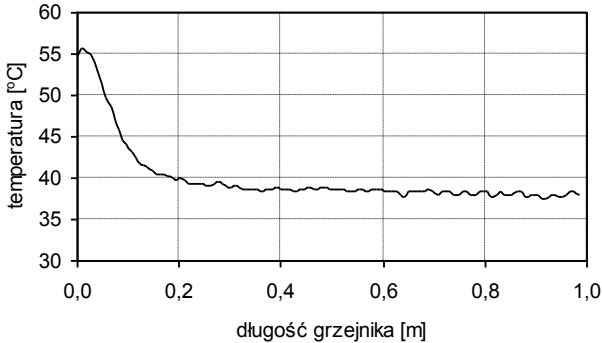

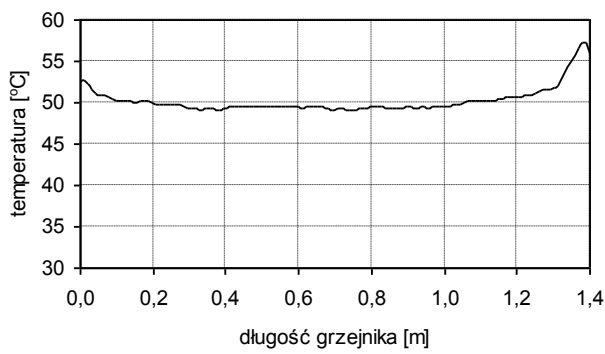

Figure 6. Thermograms of radiators in conditions of wrong hydraulic adjustment 